\title{
Interlayer expansion of large single crystals of lamellar titanosilicate JDF-L1 with
}

\section{1,6-hexanediamine}

Li Zhang a , Jingyu Han ${ }^{\text {a }}$, Yingjie Jin ${ }^{\mathrm{a}, *}$, Shudong Zhang ${ }^{\mathrm{b}}$, Sachio Asaoka ${ }^{\mathrm{c}}$, Shanlin Zhao ${ }^{\mathrm{a},}{ }^{\S}$

a School of Petrochemical and Technology, Faculty of Chemistry and Chemical-Environmental Engineering, Liaoning Shihua University, Fushun 113001, Liaoning Province, PR China

${ }^{b}$ Fushun Research Institute of Petroleum and Petrochemicals, Sinopec, Fushun 113001, Liaoning Province, PR China

$c$ Department of Chemical Processes and Environments, Faculty of Environmental Engineering, University of Kitakyushu, Kitakyushu 808-0135, Fukuoka, Japan

Abstract: Lamellar titanosilicate JDF-L1 was obtained in a $\mathrm{F}^{-}$-containing gel without using organic reactants. The lamellar JDF-L1 crystals in proton-form were intercalated with an aqueous 1.6-hexanediamine solution. Distinct lattice dilations were validated featuring of $c$-axis direction and led to an increase of ca. $4.95 \AA$ in $d_{001}$ interplanar spacing. The textural modification toward lamellar JDF-L1 crystals provided a new delaminated titanosilicate material with layered JDF-L1 structure.

Keywords: Porous materials; JDF-L1 single crystal; Interplanar spacing; Lattice dilation; Crystal structure

\section{Introduction}

JDF-L1 is a non-centrosymmetric, tetragonal layered titanosilicate with the microporous framework containing five-coordinate $\mathrm{Ti}$ (IV) ions in the form of $\mathrm{TiO}_{5}$ square pyramids [1], where each of vertices of the base is linked to $\mathrm{SiO}_{4}$ tetrahedra to form continuous sheets with exchangeable interlamellar $\mathrm{Na}^{+}$ions

\footnotetext{
* Corresponding author. Tel.: +86 24 56860797; Fax: +86 24 56860958. E-mail address: jinyingjie512@163.com (Y Jin).

$\S$ Ccorresponding author. E-mail address: Inshjpaper@163.com (S Zhao).
} 
[2]. Such layered materials have potential applications in hybrid-membrane manufacture, electronic arrays and particularly in hydrogen storage [3].

The synthesis of large single crystals of zeolites enables the structure refinement to be understood at a fundamental level. Delamination of layered titanosilicates via interlayer expansion provides the functional materials tailored toward special applications [4]. An alternative route is the synthesis of zeolites in $\mathrm{F}^{-}$-containing titanosilicate gels with a neutral or low alkali $\mathrm{pH}$ region [5]. Lamellar JDF-L1 crystals were recently synthesized from lower $\mathrm{pH}$ gel phases upon a fluoride solution-mediated growth mechanism. The occurrence of lamellar JDF-L1 phase substantiated the space group $\left(P 42_{1} 2\right)$ typical of crystallographic symmetries [6]. With respect to JDF-L1 structural tailoring, intercalation with bigger molecules would offer an opportunity to use these delaminated microporous materials. In this context, a new material UZAR-S1 was obtained by exfoliating the layered JDF-L1 [7], leading to the enhanced permselectivity of $\mathrm{H}_{2}$ in $\mathrm{H}_{2} / \mathrm{CH}_{4}$ mixture [8]. Further interlayer expansion and even exfoliation of lamellar JDF-L1 crystals are likely to facilitate the formation of finely lamellar structures for the fabrication of discrete nanosheet building units with which to reassemble a series of high surface area derivates.

In this communication, interlayer expansion of lamellar JDF-L1 crystals was investigated in the presence of 1,6-hexanediamine considered the affinity of protonated JDF-L1 for guest molecules. Significant results concerning alterations in unit-cell parameters and interlayer spaces were achieved by following the ideas set out.

\section{Experimental}

2.1 Synthesis and intercalation of lamellar JDF-L1

Titanosilicate JDF-L1 crystals with lamellar architecture (lamellar JDF-L1) were synthesized in a 
$\mathrm{Na}_{2} \mathrm{O}-\mathrm{SiO}_{2}-\mathrm{TiO}_{2}-(\mathrm{KF})-\mathrm{H}_{2} \mathrm{O}$ system consisting of only inorganic reactants. More details on the synthesis procedure were described elsewhere [6]. Lamellar JDF-L1 was ion-exchanged at ambient temperature using an aqueous hydrochloric solution $(0.2 \mathrm{M})$ and was maintained at a final $\mathrm{pH} 2.0$ for $24 \mathrm{~h}$. The protonated lamellar JDF-L1 (lamellar H-JDF-L1) was collected by thoroughly washing with deionized water and drying at $110^{\circ} \mathrm{C}$ for $24 \mathrm{~h}$. Lamellar H-JDF-L1 was intercalated with an aqueous organic amines solution. Typically, a preparative mixture of $1.5 \mathrm{~g}$ lamellar H-JDF-L1 and $60 \mathrm{ml}$ 1,6-hexanediamine (0.6 M) was hydrothermally treated at $80^{\circ} \mathrm{C}$ for $120 \mathrm{~h}$ in a Teflon-lined autoclave. The resulting solid, designated as swollen JDF-L1, was washed thoroughly and dried in an oven at $110^{\circ} \mathrm{C}$ for $24 \mathrm{~h}$.

\subsection{Characterization}

Powder X-ray diffraction (XRD) patterns were collected on a Rigaku D/max-2400 diffractometer with $\mathrm{CuK} \alpha$ radiation $(\lambda=0.15418 \mathrm{~nm})$ in the scanning range of $5-60^{\circ}(2 \theta)$ and unit cell parameters were calculated using an indexing program of MID jade 6.5. Fourier transform infrared spectroscopy (FTIR) was performed on a Spectrum GX spectrometer equipped with an infrared DTGS detector. Spectra were recorded with $4 \mathrm{~cm}^{-1}$ resolution in the range of $4000-400 \mathrm{~cm}^{-1}$. Scanning electron microscopy (SEM) images were obtained on a JSM-7500F over gold-coated specimens by operating at $20 \mathrm{kV}$, this equipment allowed energy dispersive $\mathrm{X}$-ray (EDX) analyses in the selected areas which were in principle focused on single crystals. $\mathrm{N}_{2}$ adsorption at $77 \mathrm{~K}$ was performed on a Micromeritics ASAP 2420 apparatus. Prior to measurements, samples were degassed for $16 \mathrm{~h}$ at $623 \mathrm{~K}$ under around $10^{-4} \mathrm{~Pa}$.

\section{Results and discussion}

As shown in Fig. 1, the XRD pattern of lamellar JDF-L1 reveals reflections characteristic of titanosilicate JDF-L1 structure [2]. The intensive (001) and (002) reflections at $8.277^{\circ}$ and $16.510^{\circ}(2 \theta)$, 
respectively, indicate preferential growth of large size crystals in relevant crystallographic orientations compared with normal JDF-L1 crystals synthesized previously [5]. Lamellar H-JDF-L1 crystals are shown to have a few equivalent $(00 l)$ reflections shifting to the wide-angle range, resulting in a lattice contraction in $a$ - and $c$-axis directions. The XRD pattern of swollen JDF-L1 exhibits the renewing (001) and (002) reflections corresponding to $5.653^{\circ}$ and $16.871^{\circ}$ (Fig. A1), followed by a $73 \%$ loss of relative crystallinity to initial lamellar JDF-L1. The initial (001) reflection at $8.277^{\circ}$ was seen to extend $2.624^{\circ}$ toward a low-angle region, whereas no discernible peak occurred in the low-angle range as shown in the insert. Also, the minor reflection at $9.317^{\circ}$ for swollen JDF-L1 was indexed associated with its precursor remaining (001) plane, referred to as (001') in Fig. 1c. Crystal compositions (Table 1) of lamellar JDF-L1 are close rather to the theoretical values of layered JDF-L1 crystals [1]. Intercalation of lamellar JDF-L1 by 1,6-hexanediamine led to an increase in unit-cell dimension, $c$, and in $\mathrm{d}_{001}$ interplanar spacing, giving rise to a swollen fraction of ca. $81 \%$ based on the relative intensity of the remaining (001') to resulting (001) reflections [8]. In short, these results imply oriented lattice dilations in view of the $d$-spacing and $c$ values. Atomic Si/Ti ratios in swollen JDF-L1 framework seem relatively constant despite further loss of alkali metal ions.

Upon framework vibration FTIR spectra in Fig. 2, the asymmetric stretching vibration of $\mathrm{Si}-\mathrm{O}-\mathrm{Ti}$ linkages defined in JDF-L1 structure [2] shifts from 1086 to $1045 \mathrm{~cm}^{-1}$ [9] and the bending vibration of short $\mathrm{Ti}-\mathrm{O}$ bonds in five-coordinate $\mathrm{TiO}_{5}$ also shifts from 864 to $770 \mathrm{~cm}^{-1}$ [10]. Both of the visible red-shifts indicate that interlayer intercalation with 1,6-hexanediamine impacted on the framework Ti (IV) chemical locations occupied initially by $\mathrm{Na}^{+}$ions and water and hence led to alterations both in cell parameters and $d_{001}$ interplanar spacings. 
Normal JDF-L1 crystals have proven to grow upon the stacked layered structures profiled like a square-pyramid [6]. However, the SEM image (Fig. 3a) of lamellate JDF-L1 crystals grown in the $\mathrm{F}^{-}$-free hydrothermal system shows unique square-sheets of large single crystals with the three dimensions of ca. $15 \times 15 \times 1.5 \mu \mathrm{m}$ in three dimensions. Note that the large single crystal habit of lamellate JDF-L1 differs from the multi-layered morphologies of normal JDF-L1 crystals [7]. To focus immediately on the images in both Fig. 3b and the inset, swollen JDF-L1 crystals present a distinct expansion of interlayer spaces in nanosized scope, yielding an increased thickness of at least $2.0 \mu \mathrm{m}$ in lateral faces. No obvious dimensional change in the basal plane was observed upon extensive SEM results. This observation on crystal morphologies coincides with XRD results for initial and modified samples.

As for the $\mathrm{N}_{2}$-adsorbed behavior illustrated in Fig. 4, the comparison of adsorption-desorption isotherms between initial and modified samples indicates that: (i) lamellar JDF-L1 crystals were not competent for adsorbing nitrogen due to the geometry limitation of framework micropores (ca. $0.3 \mathrm{~nm}$ ) [8] and the discrete characteristic of single crystals; (ii) swollen JDF-L1 was confirmed to have an enhanced $\mathrm{N}_{2}$-adsorption capacity $\left(0.146 \mathrm{~cm}^{3} / \mathrm{g}\right)$ coupling with hierarchical pore-size distribution (Fig. A2). The specific surface area by BET method was three times larger for swollen JDF-L1 $\left(56.7 \mathrm{~m}^{2} / \mathrm{g}\right)$ than for processor lamellar JDF-L1 $\left(14.2 \mathrm{~m}^{2} / \mathrm{g}\right)$. The improved textural properties of swollen JDF-L1 evidenced the role of intercalation on interplanar spacings opening in (001) orientation and are expected to favor homogeneous dispersion of the delaminated sheets in composite polymer matrices [3].

\section{Conclusions}

Large single crystals of lamellar JDF-L1 were obtained in a $\mathrm{F}^{-}$-containing titanosilicate gel without using organic reactants. Lamellar JDF-L1 crystals in proton form were intercalated with an aqueous 
1.6-hexanediamine solution. The distinct lattice dilation of featuring (001) orientation texture led to an increase of $5.22 \AA$ in unit-cell dimension, $c$, and of $4.95 \AA$ in $d_{001}$ interplanar spacing. The textural modification toward lamellar JDF-L1 crystals provided a new delaminated titanosilicate material with layered JDF-L1 structure.

\section{Acknowledgements}

The National Science Foundation of China (No. 21171083) provided the additional financial support for the successive research.

\section{References}

[1] Roberts MA, Sankar G, Thomas JM, Jones RH, Du H, Chen J, Pang W, Xu R. Nature $1996 ; 381: 401-4$

[2] Rubio C, Casado C, Uriel S, Téllez C, Coronas J. Mater Lett 2009;63:113-5.

[3] Bian C, Wu Q, Jian Zhang J, Fang Chen, Shuxiang Pan, Liang Wang, et al. Microporous Mesoporous Mater 2015;214:204-9.

[4] Casado C, Ambroj D, Mayoral Á, Vispe E, Téllez C, Coronas J. Eur J Inorg Chem 2011:2247-53.

[5] SunY, Zhang F, Du X, Liu X, Chu G, Zhang S, Jin Y. Mater Lett 2013;97:31-3.

[6] zhang L, Li J, Jin Y, Zhang S, Sun S, Zhao S. Mater Lett 2016;176:219-22.

[7] Rubio C, Casado C, Gorgojo P, Etayo F, Uriel S, Tellez C, et al. Eur J Inorg Chem 2010:159-63.

[8] Galve A, Sieffert D, Vispe E, Téllez C, Coronas J, Staudt C, et al. J Membr Sci 2011;370:131-40.

[9] Lin Z, Rocha J, Brandao P, Ferreira A, Esculcas AP, de Jesus JDP, Philippou A, Anderson MW. J Phys Chem B 1997;101:7114-20.

[10] Du H, Fang M, Chen J, Pang W. J Marrer Chem 1996; 6:1827-30. 
Figure 1

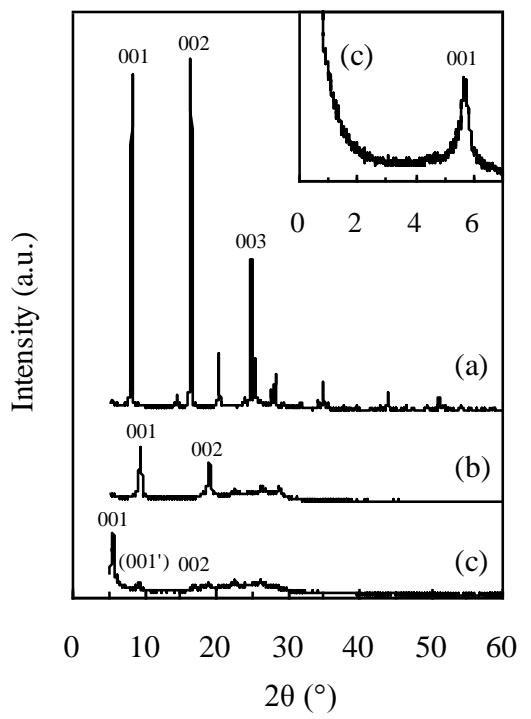

Fig. 1. XRD patterns of (a) lamellar JDF-L1, (b) lamellar H-JDF-L1 and (c) swollen JDF-L1 (the insert shows the low-angle pattern of swollen JDF-L1).

\section{Figure 2}

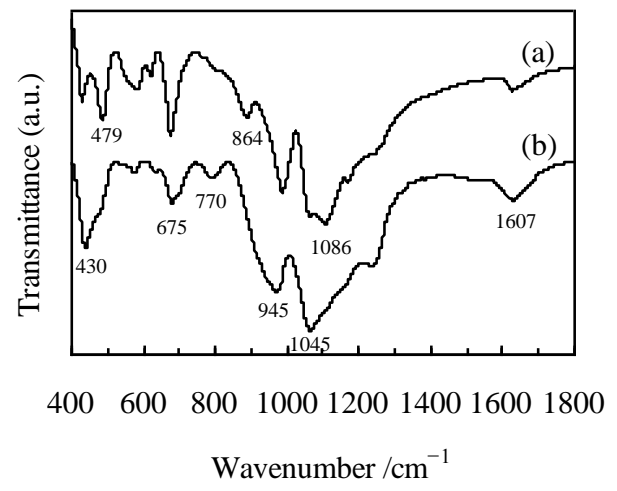

Fig. 2. FTIR spectra of (a) lamellar JDF-L1 and (b) swollen JDF-L1.

Figure 3

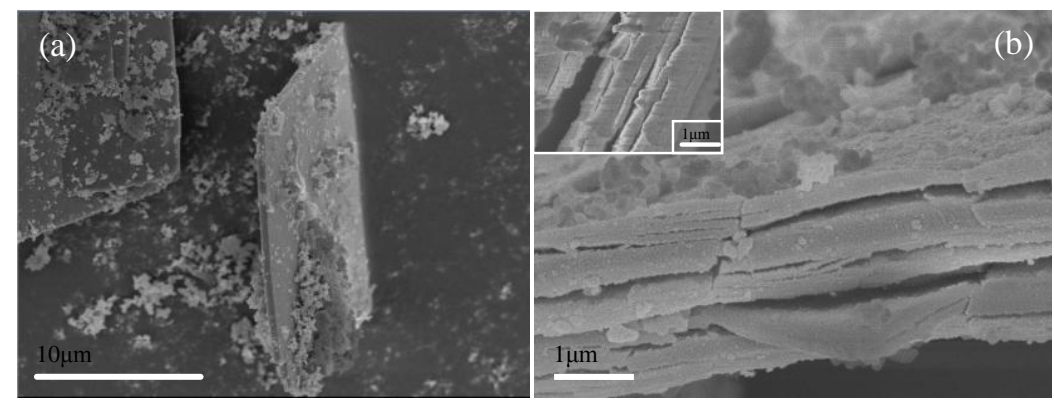

Fig. 3. SEM images of (a) lamellar JDF-L1and (b) swollen JDF-L1. 


\section{Figure 4}

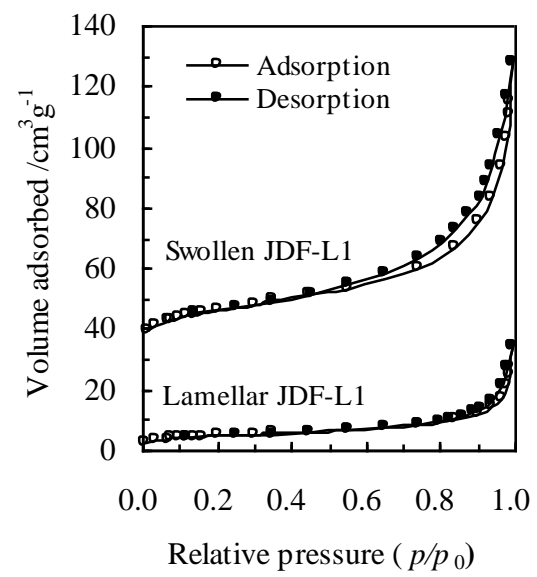

Fig. 4. $\mathrm{N}_{2}$ adsorption-desorption isotherms of lamellar JDF-L1 and swollen JDF-L1.

Table 1 Crystal compositions by EDX and crystallographic parameters of lamellar JDF-L1 and the protonated and intercalated samples thereof.

\begin{tabular}{lllll}
\hline Sample & $(\mathrm{Na}+\mathrm{K}) / \mathrm{Ti}$ & $\mathrm{Si} / \mathrm{Ti}$ & Tetragonal unit-cell dimensions ${ }^{a}$ & Interplanar spacing, $d_{001}$ \\
& $($ atomic ratio $)$ & (atomic ratio) & & \\
& & & & \\
\hline Theoretical JDF-L1 [1] & $2.0(\mathrm{Na})$ & 4.0 & $a=7.3673 \AA, c=10.6998 \AA$ & $10.700 \AA$ \\
Lamellar JDF-L1 & $2.1 \pm 0.12$ & $4.7 \pm 0.08$ & $a=7.3867 \AA, c=10.6166 \AA$ & $10.674 \AA$ \\
Lamellar H-JDF-L1 & & & \\
Swollen JDF-L1 & $0.3 \pm 0.06$ & $4.5 \pm 0.10$ & $a=6.5912 \AA, c=15.8364 \AA$ & $15.620 \AA$ \\
\hline
\end{tabular}

${ }^{a}$ The $c$-axis is also in the (001) orientation perpendicular to the layers. 
Graphical Abstract

Graphical abstract

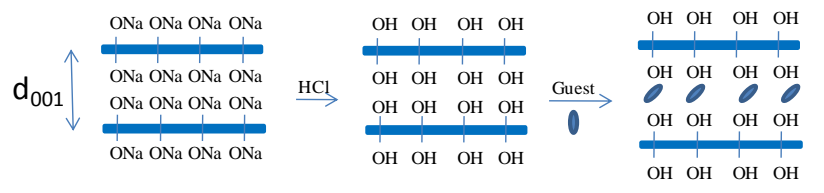

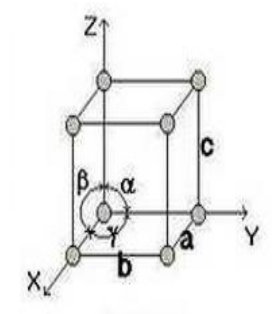

